\title{
Crítica de Processo e Educação: possíveis diálogos
}

\section{Cecilia Almeida SALLES*}

* Pós-Doutora (2016) em Cinema, Rádio e Televisão pela Universidade de São Paulo (USP). Professora Titular da Pontifícia Universidade Católica de São Paulo (PUC/SP). Contato: cecilia.salles@gmail.com.

\section{Resumo:}

O objetivo do artigo é fazer uma reflexão sobre as possíveis relações entre a crítica de processo e a educação. Será feita uma apresentação desta abordagem crítica e de alguns aspectos relevantes do conceito de criação como rede - Pierre Musso, 2004 -, de base semiótica - Charles Sanders Peirce -, para a nos aproximarmos de algumas especificidades dos processos educacionais que envolvem interações entre alunos, professores e escolas. Serão apresentados alguns resultados das pesquisas sobre processo de criação em grupo ou equipe, em diálogo com Domenico De Masi (2005, 2007), Steven Johnson (2011) e Edgar Morin $(2002,2009)$, dando destaque à escassez de bibliografia nesta área. Em seguida, será discutida, de modo mais específico, a relação entre professores e alunos, destacando a relevância do acompanhamento e consciência de processos e seus efeitos sensíveis, em meio à possibilidade de erros e necessidade de pesquisa. Por fim, no contexto da relação dos professores e escola, serão apresentados alguns aspectos relevantes dos processos de criação em grupo como contexto de produção, construção de projetos em comum, comunicação destes projetos e efeitos subjetivos no contexto dos encontros.

\section{Palavras-chave:}

Crítica de processo. Processo educativo. Processo de criação em grupo.

Signum: Estudos da Linguagem, Londrina, v. 23, n. 2, p. 72-83, ago. 2020 


\title{
Crítica de Processo e Educação: possíveis diálogos
}

\author{
Cecilia Almeida Salles
}

\section{INTRODUÇÃo}

Nosso objetivo neste artigo é propor uma reflexão sobre alguns desdobramentos da crítica de processos de criação para o campo da educação. Como os questionamentos aqui apresentados ainda estão em estado potencial, não pretendemos oferecer respostas, mas pensar junto com todos os envolvidos em processos educacionais. Para tal empreitada, estabeleceremos diálogo com o artigo Da crítica genética à crítica de processo: uma linha de pesquisa em expansão (SALLES, 2017a), que apresenta um histórico do desenvolvimento desta abordagem teórica, marcado por expansões, ajustes e ampliação de objetivos.

Partimos, assim, de uma pesquisa sobre processos de criação em grande diversidade de áreas como artes visuais, cinema, artes cênicas, literatura, arquitetura, design, fotografia, jornalismo, publicidade e curadoria, a partir do estudo de registros escritos, visuais, orais, audiovisuais, analógicos e/ou digitais, ou seja, arquivos das criações tomados como índices de desenvolvimento do pensamento em processo. O aspecto interdisciplinar desta abordagem oferece, portanto, a possibilidade de serem feitos estudos também na educação.

Vale ressaltar que foi uma pesquisa gerada pelas dificuldades sentidas na sala de aula de redação em língua estrangeria (inglês), e o estudo dos registros do processo do escritor Ignácio de Loyola Brandão, feitos ao longo da criação de seu romance Não Verás País Nenhum, parecia oferecer um caminho profícuo para compreender, em maior profundidade, o processo de escritura. Oferecia, ao mesmo tempo, uma abordagem crítica para a literatura, com foco nos processos de produção, ou seja, em como as obras são construídas. Os documentos do escritor traziam à tona camadas de trabalho e múltiplas interações responsáveis pela construção de uma complexa rede, afastando-se do conceito romântico de criação como inspiração, ou insight mágico, sem explicação.

A diversidade de pesquisas levou-nos a observar recorrências, ou seja, aspectos comuns a muitos processos que viabilizaram a sistematização, ao longo do tempo, de uma teoria crítica de processo que discute a criação como rede em permanente construção, em diálogo com o conceito de semiose (movimento do signo) nos termos de Charles S. Peirce (1994) e rede, de Pierre Musso (2004). Apresentaremos, mais adiante, algumas dessas características gerais dos processos de criação que parecem ser relevantes para estas reflexões.

Continuando, passamos a discutir também os processos de criação coletivos, gerando o livro Processos de Criação em Grupo (SALLES, 2017b). Acreditamos que alguns dos diálogos observados entre os membros das equipes são relevantes para esta discussão. É importante destacar que foi observado que há uma grande escassez de estudos sobre processos em equipe. Neste contexto, passamos a dialogar com Domenico De Masi (2007) e Steven Johnson (2011), que foram de extrema relevância para o desenvolvimento de nossa pesquisa.

De Masi (2005a, p. 94) afirma que se surpreende com o fato de que quase não existam estudos sobre a criatividade coletiva e afirma que "a criatividade individual foi mais estudada, sobretudo sob o perfil psicológico e psicanalítico”. Em outra obra, De Masi (2005b), fala que faltam estudos mais profundos sobre a criatividade coletiva. Ele observa a influência exercida pelos fatores externos sobre a fecundidade dos atos criativos. 
Desde muitos anos até hoje, a maioria dos produtos estéticos e científicos - filmes, publicidade, design, planos urbanos, descobertas físicas e biológicas, fármacos, cenários econômicos - é fruto de criação coletiva e parece cada vez mais evidente que a atribuição de obras criativas a um único responde somente a exigências de familiaridade definida, de praticidade jurídica, de arrogância majestática (2005b, p. 94).

Destacamos, nestas afirmações de De Masi, a relevância de estudos sobre os grupos criativos, a constatação da maior quantidade de pesquisas sobre o ato criativo que enfocam os processos individuais e sua contribuição para ampliação dessa bibliografia, especialmente no caso dos estudos sobre os processos educacionais que também são desenvolvidos, a nosso ver, por grupos criativos.

De Masi (2007) enfatiza, em vários momentos, que a maior parte das criações humanas não é obra de gênios isolados, mas de grupos e comunidades, e que o verdadeiro sujeito histórico da criação não é o homem, mas a sociedade.

Colocamos, no entanto, em dúvida, algumas de suas certezas, como o próprio isolamento do gênio e a delimitação dos campos das abordagens sobre os processos individuais. Por um lado, a visão da criação em meio a uma grande diversidade de interações acima mencionada, nos afasta do mito do gênio que cria a partir do nada. Ainda de modo inicial, não podemos deixar de mencionar a relevância desta perspectiva no contexto das produções dos alunos, que foram as inquietações pedagógicas detonadoras de nossa pesquisa.

Ao mesmo tempo, a crítica de processo já vem desenvolvendo um grande número de pesquisas sobre os processos no cinema, nas artes cênicas, no design e na publicidade, e agora começamos a pensar sobre a educação. Os estudos De Masi (2007) passam pela educação, como veremos mais adiante. Um dos membros de sua equipe de pesquisadores dedicou-se ao debate sobre a Bauhaus. No entanto, parece ser visto como um caso isolado de interação entre "gênios" da arte e do design.

Outra questão relevante trazida pelo trabalho de De Masi é o fato de que, ao oferecer uma perspectiva histórica dos modos de organização de grupos criativos, sob o prisma da sociologia do trabalho, discute diferentes buscas e modos de trabalho, ao longo do tempo (de 1850 a 1950). Em seus outros livros, seu olhar se aproxima ainda mais do fim do século XX. Discute, entre muitas outras questões, características dos grupos e sujeitos envolvidos, tipos de interação e de lideranças.

Esta perspectiva nos afasta de tentativas de associação destes modos de interação ou destes aspectos do funcionamento das redes de grupos criativos a um determinado momento histórico, especialmente à experimentação contemporânea. Essa abordagem não leva a uma ênfase excessiva às modificações dos modos de interação no contexto das mídias sociais, que somente amplia a diversidade de suportes e diminui o tempo das interações, sempre existentes, porque necessárias para o desenvolvimento do pensamento em grupo.

Algo semelhante acontece no livro De Onde Vêm as Boas Ideias, de Steven Johnson (2011). O autor parte da análise de uma grande diversidade de processos criativos, em diferentes campos, com o objetivo de compreender os modos como as novas ideias são formuladas. O autor busca de "propriedades e padrões compartilhados que ocorrem reiteradamente em ambientes de excepcional fertilidade” (p. 20). Suas fontes de pesquisa dialogam de modo direto com aquelas com as quais a crítica de processo lida. Como exemplo temos as constantes referências aos diários de Charles Darwin em suas viagens no Beagle, além da discussão, em um capítulo específico, de filmagens de grupos de estudo em laboratórios, ao longo de um processo de pesquisa, que serão discutidas posteriormente.

Foi de grande relevância, para a continuidade de nossa pesquisa sobre processos de criação, encontrar De Masi e Steven Johnson buscando, de modo bastante semelhante, porém por outros caminhos teóricos, generalizações sobre tais processos, a partir de estudos de casos específicos.

Talvez o único aspecto que nos afasta é que De Masi, em alguns momentos, e Steven Johnson, constantemente, buscam oferecer um caminho para promover a criatividade em âmbito social e medir e oferecer 
meios para nos tornarmos mais inovadores. Diz Johnson (2011, p. 20): “quanto mais abraçarmos esses padrões - em nossos hábitos de trabalho e hobbies pessoais, em nossos ambientes de trabalho, no projeto de novas ferramentas de software - mais capazes seremos de explorar nossa extraordinária capacidade de pensamento inovador".

Tentamos negar em nossas pesquisas, de modo bastante enfático, a perspectiva prescritiva do como deve ser feito, ou seja, oferecer modelos a serem seguidos. O que buscamos é compreender e mapear as características gerais dos processos de criação que nos auxiliam a nos aproximar das complexas singularidades.

Neste contexto, o que nos atrai em Steven Johnson, além da metodologia já mencionada, é a natureza dos "padrões compartilhados" aos quais ele chega, que são associáveis às formulações de hipóteses (abduções em termos peirceanos) que desenvolvi no livro Redes da Criação (SALLES, 2006). Quando discutimos diálogos de linguagens e interações cognitivas no âmbito das tramas do pensamento, há muitos pontos em comum com os padrões compartilhados e outros que eu não havia observado.

Já no caso de De Masi (2007), é interessante quando ele coloca o objetivo de compreender "quais as particularidades organizacionais que caracterizam a criatividade em grupo" (p. 18), que toma a maior parte de sua pesquisa.

No entanto, nos dois casos sentimos falta de instrumentos teóricos que mostrem o que leva os sujeitos em criação para determinados caminhos e não outros. Estamos falando dos princípios que direcionam as escolhas ao longo dos processos, aos quais retornaremos mais adiante.

Passamos, assim, à apresentação de alguns aspectos do conceito de criação que sustentam a crítica de processo e que nos auxiliarão no estabelecimento da relação proposta.

\section{Criação COMo Rede}

Primeiro aspecto a destacar é o fato de tratar-se de um percurso de construção (ação/conflito/ confronto/encontros), sensível e intelectual ${ }^{1}$, sofrendo intervenções do consciente e do inconsciente. Afasta-se, assim, da dicotomia intelectual ou sensível, que ainda rege as discussões de muitos pensadores da criação, vendo, por exemplo, o processo da ciência como objetivo e intelectual e o da arte, subjetivo e sensível. O que se está propondo aqui é que todos os processos convivem com estes três aspectos. As diferenças são de outra ordem, como a natureza da busca ou da tendência, como veremos.

A rede da criação se constitui ao longo de um processo contínuo de interações com tendências. É um percurso, sem ponto inicial nem final, falível, sustentado pela lógica da incerteza, englobando a intervenção do acaso e abrindo espaço para a introdução de ideias novas.

As tendências, sob o ponto de vista semiótico, são rumos vagos que orientam o processo de construção dos objetos, no ambiente de incerteza e imprecisão. Geram trabalho em busca de algo que está por ser descoberto. O desenvolvimento do processo leva a tomadas de decisão que acarretam diminuição da vagueza, oferecendo à obra em construção contornos mais definidos. Estes rumos podem ser observados sob duas perspectivas: constituição de projetos, artísticos ou educacionais, por exemplo, e práticas comunicativas.

Neste contexto de tendências vagas está, portanto, o projeto do artista ou educador, que são princípios direcionadores, de natureza ética e estética, presentes nas ações criadoras, relacionados à produção de uma obra específica e que atam a obra daquele criador, como um todo. São as teorias implícitas no fazer, relativas à singularidade do artista. São planos de valores, formas de representar o mundo, gostos e crenças que regem

\footnotetext{
${ }^{1}$ Refiro-me às três categorias da fenomenologia de Charles S. Peirce.
} 
o seu modo de ação. Esse projeto está inserido no espaço e tempo da criação que, inevitavelmente, afetam o artista ou educador. Envolve conceitos de educação, modos de trabalho etc.

Já as reflexões sobre as tendências dos processos, sob o ponto de vista das práticas comunicativas, dialogam com a constatação de Mário de Andrade (1989, p.61), que "a arte é social porque toda obra de arte é um fenômeno de relação entre seres humanos". O processo de criação mostra-se, também, como uma tendência para outros, na medida em que está inserido nas complexas redes culturais. Estamos falando das interações que alimentam os processos.

Com este conceito semiótico de tendências dos processos de criação em mente, voltamos à crítica que fizemos, anteriormente, sobre os conceitos de criação implícitos nos estudos de De Masi e Johnson, que não discutem e nem nos dão pistas sobre critérios de escolhas ou princípios direcionadores.

O aspecto falível do processo, por sua vez, está, estreitamente, relacionado à sua continuidade, inseparável da indeterminação e da incerteza. Onde há variação contínua, a precisão é inatingível e a possibilidade de erro, inevitável. Transitoriedade acarreta a impossibilidade de se ter um conhecimento absoluto e a possibilidade de se ter um conhecimento errado.

Quanto à entrada de ideias novas, trazemos a discussão de Peirce sobre a natureza inferencial da cognição. O filósofo afirma que "toda cognição está fundada em alguma outra cognição" (CP 5.213, 1994)². Esta afirmação nos remete ao raciocínio responsável pela formulação de hipóteses, a única operação lógica que introduz uma nova ideia. Em termos peirceanos, falamos da abdução, um dos modos de desenvolvimento do pensamento que deixa transparecer a natureza indutiva da criação. Neste momento de concretização da obra, hipóteses de naturezas diversas são levantadas e vão sendo testadas. Encontramos experimentação em rascunhos, versões de programas de disciplinas, registros de aula dos professores, assim como esboços de artistas, por exemplo. É importante enfatizar, portanto, que há experimentação ou testagem de hipóteses em todos os processos, o que difere é a natureza das tendências ou das buscas. Daí podermos falar de hipóteses educacionais, no contexto destas reflexões.

Demos destaque, até aqui, ao ambiente de incerteza, ao aspecto sensível, às interações, ao erro e à entrada de novas ideias, em meio a experimentações.

Caminhando na apresentação de alguns aspectos gerais do processo de criação, que parecem interessantes para se pensar as interações da crítica de processo com a educação, trazemos de volta a discussão das duas dimensões das tendências observadas nas redes da criação: construção do projeto e práticas comunicativas.

Acreditamos que pensar a inter-relação destas dimensões das tendências dos processos de criação possa ser um caminho fértil para ativar a complexidade dos processos, em grupo ou equipe. Percursos imersos no contexto acima descrito, da incerteza, possibilidade de enfrentamento de erros, conflitos e, ao mesmo tempo, com o potencial de novas possibilidades. Construção de um projeto comum na interação entre sujeitos que têm seus projetos pessoais. Daí a importância de se observar a construção de projetos comuns, em meio às práticas comunicativas, ou seja, na interação entre os membros dos grupos.

Neste contexto, é importante discutir também o processo de comunicação dos projetos em construção. Diante das dificuldades da comunicação entre os membros do grupo, trazemos uma citação do coreógrafo e bailarino Alwin Nikolais, bastante eloquente: "coreografar para outra pessoa é como entregar a alguém um punhado de areia. Muita coisa se perde. Mas a gente aprende a se contentar com uma percentagem razoável" (NIKOLAIS apud LOUIS, 1992, p. 133).

\footnotetext{
${ }^{2}$ Modo de citação dos Collected Papers de Charles S. Peirce: vol. 5 páragrafo 213.
} 
A partir do olhar geral da crítica de processo, vamos nos aproximar de algumas especificidades dos processos de criação na educação.

\section{Algumas Reflexões sobre os Processos Educacionais}

Podemos observar os processos educacionais que envolvem alunos, professores e escolas, no âmbito dos processos em equipe. Em outras palavras, trata-se de um campo de ação que se dá, necessariamente, em interações que sustentam as redes da criação.

Para discutir estas interações, passo a dialogar com Morin (2002), Steven Johnson (2011) e Colapietro (2014). Segundo Colapietro, os processos em grupo são formados por sujeitos como comunidade. O autor afirma que o sujeito não é uma esfera privada, mas um agente comunicativo. É distinguível, porém não separável de outros, pois sua identidade é constituída pelas relações com outros; não é só um possível membro de uma comunidade, mas a pessoa, como sujeito, tem a própria forma de uma comunidade.

Interessante relacionar este sujeito, descrito por Colapietro, com o conceito de "rede líquida" de Steven Johnson (2011, p. 20): uma das propriedades compartilhadas por diferentes ambientes, considerados de excepcional fertilidade. O autor relata descobertas de uma pesquisa de Kevin Dunbar (psicólogo da McGill University/EUA), em um laboratório de biologia molecular. Observou-se, a partir dos registros audiovisuais mencionados, que a maioria das ideias importantes vinha à tona durante reuniões regulares, nas quais vários pesquisadores se encontravam e, de maneira informal, apresentavam e discutiam seu trabalho mais recente.

Ao observar o mapa da formação de ideias criado por Dunbar, ficou evidente que o ponto de partida da inovação não era o microscópio, mas a mesa de reunião. O fluxo social da conversa em grupo transforma esse estado sólido privado numa rede líquida.

Conviver em ambiente de interações propicia a explicitação de problemas. Os resultados do raciocínio de uma pessoa podem tornar-se o input para o raciocínio de outra, podendo levar a descobertas importantes. A rede líquida impede que ideias fiquem emperradas em preconceitos. Dá-se destaque, também, à interatividade que envolve interdisciplinaridade e leva à saída dos limites dos campos e olhares especializados, ampliando os modos de percepção. Para o autor, as interações entre os membros do grupo conduzem também ao enfrentamento da incerteza. As perguntas feitas por colegas forçam o repensar sobre o que está sendo feito e abrem espaço para a dúvida.

Segundo Johnson, a pesquisa de Dunbar sugere uma ideia vagamente tranquilizadora: mesmo com todos os avanços tecnológicos de um dos principais laboratórios de biologia molecular, a ferramenta mais produtiva para gerar boas ideias continua a ser um círculo de seres humanos, sentados em volta de uma mesa, discutindo questões de trabalho.

Hoje, em meio à pandemia, podemos pensar nos encontros remotos com algumas similaridades, enfrentando, porém, desafios no campo de concretização das interações, com a sobreposição de vozes ou mãos digitalmente levantadas.

Dando continuidade a essas reflexões sobre interação, recorremos agora a Morin (2002, p. 72), quando o autor discute a natureza de interações na cultura como ações recíprocas que modificam o comportamento ou a natureza dos elementos nelas envolvidos. Supõem condições de encontro, agitação, turbulência e tornam-se, em certas condições, inter-relações, associações, combinações, comunicações etc., ou seja, dão origem a fenômenos de organização. Há algo nas propriedades associadas à interatividade que parece ser importante destacar, para compreender as conexões da rede da criação: condições de encontro, influência mútua, algo agindo sobre outra coisa e algo sendo afetado por outros elementos. 
É interessante observar a consequência desta ação de um elemento sobre o outro, sob a forma de ramificação de novas possibilidades, na rede de criação. Ao pensar a criação sob esta perspectiva, mesmo os processos individuais já são em comunidade. Em outras palavras, a criação se dá em meio a uma grande diversidade de interações: conversa com amigos, um livro lido, um filme assistido etc. geram novas possibilidades que podem ser levadas adiante ou não. A rede ganha complexidade à medida em que novos nexos são estabelecidos.

Nos processos em equipe, as ações de cada membro passam a estar comprometidas com a construção de um projeto comum. É a busca de princípios direcionadores no contexto da coletividade. Ao mesmo tempo, são os grupos formados por sujeitos inseridos em suas redes complexas e direcionados pelos projetos pessoais que os atraem.

A descrição deste espaço de interação é bastante familiar, no âmbito das reuniões de professores e coordenadores, relações de sala de aula etc. As interações, como campo de possibilidades, ou não.

Olhemos agora, de modo mais próximo, os processos dos estudantes, dos professores e das escolas, com toda a dificuldade de segmentações, por se tratar de interações entre sujeitos, como acabamos de discutir.

\section{Processos de Alunos e de Professores}

Não há dúvida de que podemos discutir as ações dos alunos e dos professores nas salas de aula, ao longo dos semestres e/ou anos, como processo de criação com suas tendências específicas.

Neste contexto, é importante destacar que para pensarmos as reverberações da crítica de processo na educação, não precisamos passar pelo questionamento se aquilo que está sendo produzindo é arte ou não. A partir da abordagem sobre processos de criação de natureza geral, estamos sempre diante de buscas com rumos vagos, tateando, errando, formulando e testando hipóteses, fazendo escolhas, produzindo conhecimento no âmbito das especificidades do contexto educacional.

Neste primeiro momento, vamos observar os processos de criação com buscas educacionais, a partir do potencial de registros dos percursos e do aspecto sensível que lhes é inerente. Quanto aos documentos de processo, destacamos a possibilidade de estudo dos registros dos professores, sob a forma de preparação de aula, anotações de reuniões, pesquisas, só para citar alguns exemplos. O olhar teórico-crítico para esta documentação pode propiciar uma reflexão crítica sobre sua própria prática, alimentando, também, discussões mais amplas sobre os processos educacionais.

Por ter acompanhado pesquisas de outros profissionais, como o caso de jornalistas que se propuseram refletir sobre seu próprio fazer, enfatizamos o abalo de certezas e erros, gerando necessidade da formulação de novas hipóteses, em intensas experimentações, abrindo espaço para a entrada de novas ideias e um amplo campo de possibilidades.

Quanto ao aspecto sensível da criação chamamos, no livro Gesto Inacabado (SALLES, 2011) de marcas psicológicas dos percursos de todo e qualquer agente criativo. São relações tensionais que mantêm a vitalidade do processo de construção da obra e que aparecem, também, nas emoções ou sensações dos artistas, professores, alunos etc.

Naquele momento da pesquisa, ficou claro que diante de dificuldades, necessidade de resistência e de tomar consciência de problemas, o artista depara-se, também, com intensos momentos de prazer, encantamentos, fluidez de associações e ludicidade. Os projetos vão sendo construídos neste ambiente emocionalmente tensivo, em meio a prazeres e desprazeres, flexibilidade e resistência. O sensível perpassa todo e qualquer processo; daí observarmos alunos e professores também em meio a medos, prazeres, ludicidade, 
motivação, enfrentamento de problemas, incerteza etc. O importante é poder pensar na consequência desta constatação, no ambiente da escola ou universidade, como veremos adiante.

Levando adiante nossa proposta de propor uma possível aproximação entre a crítica de processo e a educação, passamos a discutir as relações professores e alunos.

\section{Relação Professor e Aluno}

Pensando em como o estudo sobre processo de criação pode lançar luzes sobre escolhas de ação, na sala de aula, destacamos a possível relevância de se pensar em acompanhamento de processos, erros, consciência de processo e de pesquisa e efeitos sensíveis.

O acompanhamento dos percursos envolve pensar ensino/ aprendizagem como processo e não como uma série de produtos, isto é, um olhar não segmentado para produções isoladas. Em consequência, olhar as produções, ao longo do ano, como registros do percurso do aluno.

Ainda nos anos de 1980, propusemos em sala de aula de redação em inglês, ainda de modo rudimentar, por não ter passado pela experiência do estudo dos arquivos de criação, de Loyola, que os alunos não fizessem redações isoladas, mas que fosse um projeto de semestre, em diálogo com os professores de literatura.

Recentemente, fomos convidadas para uma live/palestra no Instituto Iungo ${ }^{3}$, voltada à formação, pesquisa e apoio a educadores da Educação Básica, que foi detonadora das reflexões aqui propostas. Ao final, a profa. Renata Alencar, coordenadora, com a Profa. Tailze Melo, de uma residência para educadores de escolas públicas e privadas que estimula a criação e implantação de práticas pedagógicas inovadoras nas escolas, fez uma pergunta bastante instigante: como os estudos sobre processo podem colaborar com "as metodologias de aprendizagem ativa que trazem para a cena dos debates da educação as estratégias pedagógicas que colocam o estudante no centro do processo de construção de conhecimento"?

Não há dúvida de que há um salto no tempo entre a nossa experiência relatada e as metodologias de aprendizagem ativa. Acreditamos, no entanto, que a aprendizagem, baseada em projetos, dialoga de modo bastante estreito com a visão de acompanhamento de processo, aqui proposta.

Ao mesmo tempo, não podemos deixar de destacar as dificuldades do enfrentamento do erro, neste contexto. Vimos que o processo é falível. Em outras palavras, o erro é parte do processo. Há necessidade de rever o conceito de erro pré-estabelecido e aceitar como parte do processo que pode ser corrigido em diferentes momentos? Não temos resposta, mas oferecemos um espaço para reflexão.

Para discutir a consciência de processo e de pesquisa, trazemos dois exemplos. O primeiro, também da nossa "velha" sala de aula de redação, quando levamos para os alunos uma edição fac-similada, comemorativa dos quarenta anos de atividade literária de Érico Veríssimo do livro Fantoches (1972), que é assim apresentada pelos editores:

Fantoches apareceu em 1932 e não foi um livro de sucesso. Da edição de mil e quinhentos exemplares, venderamse menos de quinhentos [...] o livrinho de 1932 reaparece inteiro, página por página, e vem brilhantemente acrescido - achamos que o homenageado também tinha de trabalhar na elaboração do próprio presente e o resultado está aqui: magnífico.

Temos certeza de que o novo livro vai agradar todo mundo. Primeiro, porque tem seu valor histórico, ao reproduzir o passo inicial de um homem que se fez celebridade na literatura de sua língua; depois por vir enriquecido das impressões, tantas vez̧es irônicas, que causam no sessentão de hoje as estórias do moço estreante (p. 1, grifos nossos).

\footnotetext{
${ }^{3}$ Disponível em: https://bit.ly/3dpj87P.
} 
Ao mostrar este livro aos alunos, nosso objetivo era tornar consciente para eles o processo de autocorreção, ou revisão de um escritor. Ficava clara a diversidade de observações que ele faz: menciona a escolha de tom inadequado, palavras que não se adequavam aos personagens, comentários sobre personagens, regências suspeitas, bons temas que mereciam melhor tratamento etc.

Na mesma live, mencionada anteriormente, uma professora de artes disse que no contexto da pandemia, levava diferentes materiais para serem explorados pelos alunos. Destacamos a importância da consciência da pesquisa como parte integrante de todos os processos e, neste caso, a pesquisa que leva à experimentação dos materiais, trazendo à tona camadas de trabalho dos processos em oposição à visão de criação como insights mágicos, sem história.

Retomamos, por último, a questão do sensível na relação dos professores e alunos para pensar, de modo bastante crítico, no poder do professor, na motivação ou não dos alunos que, em muitos momentos, está estreitamente relacionada ao erro ou modo de se falar sobre os possíveis erros.

Voltemos à sala de aula e a uma inesquecível devolução de redações corrigidas e com nota. Entreguei ${ }^{4}$ a uma aluna, comentando que tinha gostado muito do texto. A nota não era muito boa e eu tinha feito o comentário para a aluna errada. Logo em seguida, pedi um trabalho em dupla em uma classe com número ímpar de alunos. Ela, cheia de confiança pelo meu comentário (e não pela nota), disse que podia deixar que faria a atividade sozinha.

Precisamos ter clareza do efeito sensível que podemos produzir nos estudantes (para o bem e para o mal). Convivendo com muitos relatos de artistas e centenas de alunos, é recorrente a experiência de bloqueios de escrita e pesquisa, a partir de comentários carregados de certeza (em um campo de incerteza) e que não levam em conta o momento do processo. Não posso afirmar que isto não tenha acontecido comigo, ao longo do tempo, mas fico sempre alerta para as dificuldades que essas certezas nossas podem causar. Claro que depende também do aluno, que pode sentir-se desafiado.

\section{Relação Professores e Escola}

Como estamos falando de um processo em equipe que envolve professores, alunos e gestores, partimos de algumas conclusões da pesquisa sobre grupos, que tem o subtítulo Diálogos, ou seja, espaço de interações. A discussão partirá de alguns aspectos envolvidos nesses processos, que podem ser detonadores para esta reflexão no campo da educação: contexto de produção, construção de projetos em comum, comunicação destes projetos e efeitos subjetivos no contexto dos encontros.

\section{Contexto de Produção}

Depois de observar os processos de muitos grupos, a partir do acompanhamento de alguns e publicações de outros, foi estabelecida relação também com a pesquisa de Domenico De Masi (2007), sociólogo do trabalho que apresenta um histórico dos grupos criativos europeus do meio do século XIX ao meio do século XX, e que discute entre outros grupos algumas escolas, como a Bauhaus, já mencionada.

Sem entrar nas especificidades dos grupos pesquisados, observamos a importância de se levar em conta o contexto de cada equipe, o que pensar em questões relativas a espaço e tempo para compreender os modos de trabalho como momento histórico, cidade, bairro etc.

\footnotetext{
${ }^{4}$ Passo a usar a $1^{\mathrm{a}}$ pessoa por envolver uma experiência muito pessoal.
} 
Compreender o contexto envolve também observar os modos e critérios de formação das equipes, modos de financiamento ou não e, especialmente, se são equipes abertas a interações e reflexões sobre o processo, como estamos propondo aqui.

Gostaríamos de destacar que o estudo de De Masi levou à observação da recorrência do caráter interdisciplinar na formação desses grupos.

\section{Construção de Projetos em Comum}

Sabemos que há princípios direcionadores de natureza geral que envolvem, por exemplo, o que se pensa de educação, metodologias de aprendizagem etc., no entanto, o projeto da escola vai se concretizando em meio às relações com a equipe (gestores, professores e funcionários). Ao mesmo tempo, cada um destes tem seus projetos educacionais próprios, que naquela escola se coloca a serviço do projeto mais amplo, com hierarquias, lideranças e opções por determinados modos de trabalho etc. Em outros contextos pesquisados, observamos muitos grupos que trabalhavam em um ambiente colaborativo, em que toda a equipe era propositiva.

É bastante recorrente nos relatos, a constatação da dificuldade de se conviver com a incerteza, na coletividade. Como discutimos anteriormente, os projetos que direcionam as ações dos grupos estão imersos no universo de vagueza e de imprecisão, gerando, na equipe, urgência por definições de rumos e clareza de critérios.

Para compreender melhor esta questão, passamos a pensar em algumas possíveis consequências da construção de projetos comuns em meio às práticas comunicativas.

\section{Comunicação dos Projetos no Âmbito das Interações entre os Membros da Equipe}

Retomamos, aqui, a citação do coreógrafo Alwin Nikolais e o punhado de areia, sabendo-se que algo fica perdido, nesse processo comunicativo.

Trazemos, agora, um exemplo do teatro para ajudar na reflexão sobre este aspecto do processo em grupo.

No Caderno de atuação (BOTELHO; MÁRMORA; ROMANO, 2013), uma publicação dos diários (editados) dos atores, produzidos ao longo do processo de criação do espetáculo Pais e Filhos, a imprecisão e incerteza deste processo se refletiam na necessidade de anotações verbais ou diagramas, na tentativa de tradução e compreensão do que o diretor queria do futuro espetáculo.

E um dos atores faz uma anotação, que é uma linha de interrogações "??????????????????????, explicando: “anoto um monte de interrogações. Entendo, mas não compreendo o que o diretor quer dizer” (p.113).

Como passar para os outros o que se quer?

Para responder a esta pergunta, recorremos ao Projeto Aesthesis: a criação em fluxo, que acompanhamos. O bailarino e coreógrafo Édi Oliveira, o diretor e performer Francis Wilker, a diretora e bailarina Kênia Dias, a coreógrafa Giselle Rodrigues, o ator e diretor Jonathan Andrade e o pesquisador Glauber Coradesqui, membros de grupos diferentes, se uniram para uma proposta de trabalho em conjunto para o Rumos Itaú Cultural, em 2015, sobre o instante, a liberdade, a escuta e a horizontalidade em processos de criação. Eles moravam em cidades diversas e tinham encontros periódicos presenciais. Ao longo do processo foram feitos registros audiovisuais e fotográficos das experimentações propostas, e houve uma intensa troca de mensagens pelo aplicativo Whats $A p p$, com o intuito de manter contato, propor ideias, discutir leituras etc.

Destacamos, assim, os registros de processo, gerados por necessidade do grupo, na construção de um projeto comum. E assim passavam uns para os outros, em ambiente colaborativo, o que queriam daquele projeto ou o que buscavam. 
A mesma necessidade levou o cineasta Evaldo Mocarzel a escrever cartas/e-mails para os montadores de seus documentários. Foi o meio encontrado por ele para passar o bastão sensível e conceitual de seu projeto cinematográfico, para outro membro da equipe. As cartas, neste contexto, são registros de interação. É uma forma de ambientação e envolvimento, no projeto em construção, feita em clima de contaminação e motivação dos montadores para participarem do projeto, o que nos leva ao último aspecto que queremos discutir sobre as relações entre os membros das equipes.

\section{Efeitos Subjetivos no Contexto dos Encontros}

Os processos em equipe são agrupamentos de sujeitos em criação, imersos em um turbilhão de sensações, que não acontecem se não forem em equipe, como o caso da escola.

Ao acompanhar diferentes processos, surgiram relatos de sentimentos como afinidade, adesão, contágio, conflitos e embates. É interessante comparar que as sensações descritas no Gesto Inacabado, já mencionadas, são focadas no sujeito, isto é, seriam intransitivas. Em contraste, no caso dos processos em grupo, falamos em afinidade com cooperação, contagiar alguém, adesão de alguém, ou seja, termos de natureza transitiva direta ou indireta, convivendo com os outros, pois grupos são formados por indivíduos. É interessante observar que a oposição tensiva se mantém: afinidade/contágio e conflitos.

Outro aspecto relevante é a recorrência do relato de conflitos entre membros dos grupos. Caristi (2007, p. 246), por exemplo, discute os embates, que levaram ao fim da Baubaus, traduzidos na diversidade de formação de profissionais, gerando a quebra da homogeneidade e comunhão de intenções "que haviam sido o ponto forte da eficiência do grupo no tempo de Gropius".

Dialogando com Morin (2010) em seu livro Ciência com Consciência, nos afastamos da utopia da necessidade de evitar ou eliminar os embates. O autor discute os campos de conflitos no contexto acadêmico. Ao propor uma sociologia da ciência, afirma que muito do que acontece nas universidades é mais geral do que se quer acreditar:

Como sabemos, o grande problema de toda organização viva - e, sobretudo, da sociedade humana - é que ela funciona com muita desordem, muitas aleatoriedades e muitos conflitos. E, como diz Montesquieu, referindose a Roma, os conflitos, as desordens e as lutas que marcaram sua história não foram apenas a causa de sua decadência, mas também de sua grandeza e de sua existência. Quero dizer que o conflito, a desordem e o jogo [...] não são resíduos a reabsorver, mas constituintes-chave de toda existência social (p. 111).

O autor reforça essa visão, afirmando que a essência das relações entre os cientistas é, ao mesmo tempo, de natureza amigável e hostil, de colaboração e competição, regida pelo jogo de verificação próprio de suas áreas.

\section{Considerações Finais}

Chegamos ao fim destas reflexões, sobre as relações entre a crítica de processo e a educação, sem respostas definitivas, modelos e teorias a serem aplicados em sala de aula, mas com um campo detonador de futuros aprofundamentos. Falamos, assim, de hipóteses responsáveis pela entrada de ideias novas, em meio a experimentações, interações múltiplas, erro, formação das equipes, buscas pedagógicas, tudo no contexto da incerteza e de processos, permeados pelo sensível. Oferecemos, finalmente, a possibilidade de se pensar em acompanhamentos de processos e reflexões críticas sobre a prática em sala de aula. 


\section{REFERÊNCIAS}

ANDRADE, M. de. O banquete. São Paulo: Livraria Duas Cidades, 1989.

BOTELHO, S.; MÁRMORA, L.; ROMANO, L. R. V. (org.). Caderno de atuação: diário da montagem de Pais e Filhos, nas manhãs, tardes e noites de 18 de maio de 2011 a 29 de setembro de 2012. São Paulo: Mundana Companhia, 2013.

CARISTI, F. Uma ponte entre artesanato, arte, indústria e academia: a criatividade racional da Bauhaus. In: DE MASI, D. (org.). A emoção e a regra: os grupos criativos na Europa de 1850 a 1950. 9. ed. Tradução Elia Ferreira Edel. Rio de Janeiro: José Olympio, 2007. p. 229-257.

COLAPIETRO, V. Peirce e a abordagem do self: uma perspective semiótica sobre a subjetividade humana. São Paulo: Intermeios, 2014.

DE MASI, D. Criatividade e grupos criativos: descoberta e invenção. v. 1. Rio de Janeiro: Sextante, 2005a.

DE MASI, D. Criatividade e grupos criativos: fantasia e concretude. v. 2. Rio de janeiro: Sextante, 2005b.

DE MASI, D. (org.). A emoção e a regra: os grupos criativos na Europa de 1850 a 1950. 9. ed. Tradução Elia Ferreira Edel. Rio de Janeiro: José Olympio, 2007.

JOHNSON, S. De onde vêm as boas ideias. Rio de Janeiro: Zahar, 2011.

LOUIS, M. Dentro da dança. Rio de Janeiro, Nova Fronteira, 1992.

MORIN, E. O Método 1: a natureza da natureza. Tradução Ilana Heineberg. Porto Alegre: Sulina, 2002.

MORIN, E. Ciência com consciência. 13. ed. Rio de Janeiro: Bertrand Brasil, 2010.

MUSSO, P. A filosofia da rede. In: PARENTE, A. (org). Tramas da rede. Porto Alegre: Sulina, 2004. p. $17-38$.

PEIRCE, C. S. The collected papers of Charles S. Peirce. Edição eletrônica reproduzindo Vols. I-VI [Hartshorne, C.; Weiss, P. (eds.). Cambridge: Harvard University, 1931-1935], Vols. VII-VIII [Burks, A. W. (ed.). Cambridge: Harvard University, 1958]. Charlottesville: Intelex Corporation, 1994.

SALLES, C. A. Redes da criação. Vinhedo: Horizonte, 2006.

SALLES, C. A. Gesto inacabado: processo de criação artística. 5. ed. rev. e ampl. São Paulo: Intermeios, 2011.

SALLES, C. A. Da crítica genética à crítica de processo: uma linha de pesquisa em expansão. Signum: Estudos da Linguagem, v. 20, n. 2, p. 41-52, ago. 2017a. DOI: http://dx.doi.org/10.5433/22374876.2017v20n2p41.

SALLES, C. A. Processos de criação em grupo: diálogos. São Paulo: Estação das Letras e Cores, 2017b.

VERÍSSIMO, É. Fantoches. Porto Alegre: Globo, 1972. 